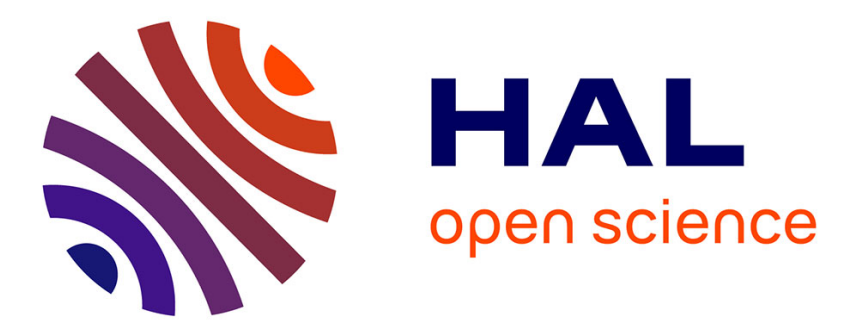

\title{
A Proposal for Risk Identification Approach in Collaborative Networks Considering Susceptibility to Danger
}

Jiayao Li, Frederick Benaben, Juanqiong Gou, Wenxin Mu

\section{- To cite this version:}

Jiayao Li, Frederick Benaben, Juanqiong Gou, Wenxin Mu. A Proposal for Risk Identification Approach in Collaborative Networks Considering Susceptibility to Danger. 19th Working Conference on Virtual Enterprises (PRO-VE), Sep 2018, Cardiff, United Kingdom. p.74-84, 10.1007/978-3-31999127-6_7 . hal-01882686

\section{HAL Id: hal-01882686 \\ https://imt-mines-albi.hal.science/hal-01882686}

Submitted on 27 Jun 2019

HAL is a multi-disciplinary open access archive for the deposit and dissemination of scientific research documents, whether they are published or not. The documents may come from teaching and research institutions in France or abroad, or from public or private research centers.
L'archive ouverte pluridisciplinaire HAL, est destinée au dépôt et à la diffusion de documents scientifiques de niveau recherche, publiés ou non, émanant des établissements d'enseignement et de recherche français ou étrangers, des laboratoires publics ou privés. 


\title{
A Proposal for Risk Identification Approach in Collaborative Networks Considering Susceptibility to Danger
}

\author{
Jiayao $\mathrm{Li}^{1}{ }^{1,1}$, Frédérick Bénaben ${ }^{2}$, Juanqiong Gou ${ }^{1}$, and Wenxin $\mathrm{Mu}^{1}$ \\ ${ }^{1}$ School of Economics and Management, Beijing Jiaotong University, Beijing, China \\ \{jiayaol,jqgou,wxmu\}@bjtu.edu.cn \\ ${ }^{2}$ Mines Albi, University of Toulouse, Albi, France \\ frederick.benaben@mines-albi.fr
}

\begin{abstract}
The paper proposes a research framework for risk identification approach in collaborative networks dedicated to develop a formalizing, structured reference for risk identification and risk mitigation and explore an effective mechanism that can motivate diverse partners to manage risks collaboratively. The approach is based on a formalized vision of Danger/Risk/Consequence chain that is defined as the primary schema of the proposed methodology. The DRC chain indicates five risk-related concepts and their interrelationships, which is able to well describe risk-related collaborative contexts. Cascading effect in the concept chain are presented for further interpreting. Furthermore, a supply chain scenario of three use cases is given to illustrate the proposed framework.
\end{abstract}

Keywords: Risk identification, DRC chain, Susceptibility to danger, Cascading effect, Collaborative network.

\section{Introduction}

A collaborative network is an alliance constituted by a variety of entities (e.g. organizations and people) that are largely autonomous, geographically distributed, and heterogeneous in terms of their operating environment, culture, social capital and goals, but that collaborate to better achieve common or compatible goals, and whose interactions are supported by a computer network [1]. Collaborative networks such as virtual organizations, dynamic supply chains, professional virtual communities, collaborative virtual laboratories, etc. are complex systems associated with uncertainties in dynamic business environments [2]. It is noted that the collaboration increases the dependences among enterprises, which makes enterprises more susceptible to risks. It is critical for collaborative networks to take systematic approaches to identify risks as early as possible, and implement appropriate strategies to manage the risk propagation throughout the evolution of collaboration [3].

${ }^{1}$ Corresponding author. 
While the above discussion shows the importance of risk identification, however, it is worthy to note that there appears to be no overarching typology to delineate exactly what constitutes risk and how to understand risk [4]. [5] argues that risk management consists of four key management aspects: (i) assessing the risk sources; (ii) defining the adverse consequences; (iii) identifying the risk drivers; and (iv) mitigating risks. [6] indicates that risk is at least made up of three essential components: (i) a driver or drivers which trigger the risk to happen; (ii) an event with probability that signifies the occurrence of the risk; and (iii) a consequence or consequences resulted from the risk. [7] presents a three-dimensional framework dedicated to structure the domain of crisis management based on the Danger/Risk/Consequence chain (DRC chain). In summary, the risk-related concepts could be concluded as danger, stake, risk, event and consequence.

Anyway, risk management is a very complex domain with a lot of constraints. Consequently, it is very difficult to get a global overview of such a domain. This article is mainly dedicated to present a proposal for risk identification approach to support collaborative networked organizations. The proposed approach is based on the DRC chain (as shown in Fig.1), which is not so far from FTA (Fault Tree Analysis) principles [8]. Furthermore, danger, risk and consequence may be considered as causal sources (in a waterfall structure) that must be formalized as models to help decision makers [7].

More specifically, the research methodology is proposed:

- A danger typology and a stake typology are developed for collaborative networked organizations based on the review of present related literatures.

- The interconnections rules between dangers and stakes and their impacts on risks could be summarized, which aims to build a risk typology as a static reference model of risk knowledge.

- In addition to danger, stake and event, risk and consequence can be also considered in a cascading effect structure [9]. Their interrelationships could be analyzed and summarized.

- A risk knowledge base with a risk typology and interrelationships is used for the deduction of risk identification rules based on previous research works.

- A metamodel connected with a risk knowledge base will be defined based on the research of collaborative situation metamodel [10,11].

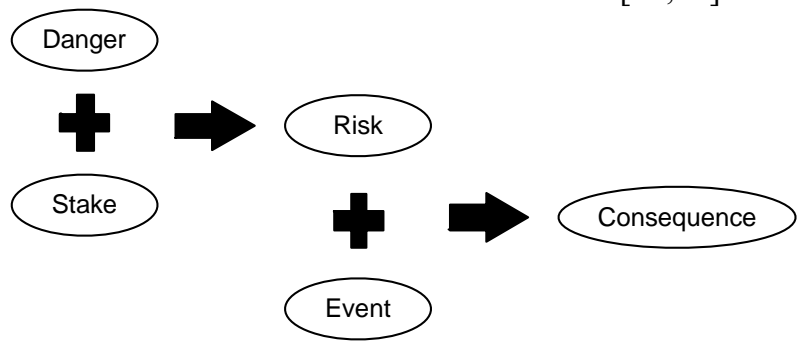

Fig. 1. A framework for risk identification approach

The research should contribute to a deeper and broader understanding risk based on the schema of DRC chain. Besides, the risk identification research based on such an understanding will contribute to better practices by suggesting collaborative responses 
from multiple partners in collaborative networks.

This article is structured according to the following sections: Section 2 presents a literature review; section 3 describes the DRC chain considering susceptibility to danger and interrelationships of the five risk-related concepts; in section 4, a supply chain scenario is given to illustrate the part of proposed methodology; section 5 concludes this research work and gives some perspectives for future works.

\section{Literature Review}

According to [12], risk is the combination of the frequency, or probability, of occurrence and the consequence of special hazardous events.

Risk Management corresponds to a set of activities that organizations use to control the many risks, which may undermine their ability to achieve objectives. Considering international standards on entrepreneurial management process risk, [13] organizes a reference risk taxonomy, which shows that risk management includes two principal dimensions, namely, assessment and treatment. Risk assessment could be summarized as three phases: analysis, identification and evaluation. Risk identification can be defined as a process of identifying the dangers, events and consequences.

It is a common assumption that participation in a collaborative network has the potential of bringing benefits to the involved partners. However, the interconnections between partners of collaborative network cause numerous new risks, of which the impacting magnitude and scope are larger than ever before [6]. In recent years, there are few studies about the risk identification of collaborative networks by considering susceptibility to danger existing in the literature of collaborative networks and further research in this field is required.

Regarding the approach of risk identification in collaborative context, it focuses on literature review, semi-structured interviews and questionnaire. They can be called as the experienced-based methods. [14] directly takes advantage of the risks identified by project manager to determine the events with negative impacts. [15] identifies the stakeholder-associated risks through the previous risk identification literatures, and classified them into seven categories. [16] identifies the risks caused by customer collaboration in product development through relevant literatures by domain experts and questionnaire in the enterprises. [17] analyzes the research paradigms regarding risk and stakeholder analysis in green buildings through literature review. [18] undertakes a systematic literature review on risks sources and resilience factors in agri-food supply chains. [19] successively uses literature review, semi-structured interviews and questionnaires to identify a list of human safety risk factors and also the cause-effect relationships among those risks.

Regarding the application of risk identification results, most results of identified risks are used to further risk evaluation and propose risk response or risk mitigation strategies. In order to investigate those risk interactions, the focus of risk evaluation methods has gradually been shifting from individual risks to networks of risk [6], [19]. It considers nodes in the network and their relationships, focusing on the 
structure and patterning of these relationships and seeking to identify both their causes and effects $[20,21]$.

We conclude the following:

- A systematic approach to the identification and categorization of risks in collaborative context is lacking.

- The current risk identification methods mainly focus on review, expert interview and questionnaire.

- $\quad$ More future works are attentive to the identification of risk interconnections.

- The present research of the application of risk identification result also lacks of a sharing-based risk response mechanism considering capabilities and resources of partners to contribute to their collaboration.

\section{Understanding Risk}

Risk can be seen as combination of the probability of an event and its consequence. However, danger and stake are also closely related to risk with the exception of the concepts of event and consequence. DRC chain is a concepts schema that is able to describe risk-related contexts.

\subsection{General Illustration of DRC Chain}

In this schema, the five risk-related concepts could be defined as follows:

- Danger can be defined as any specific dangerous characteristic of the environment, which is a signal word used to indicate an imminently hazardous situation [22].

- $\quad$ Stake or assets can be seen as item, thing or entity that has potential or actual value to an organization [23] and potential susceptibility to dangers.

- $\quad$ Risk is a potential manifestation of the danger onto some concerned stakes [7].

- $\quad$ Event is defined as a change or outcome that triggers risks. If one risk might occur it would be due to some events [24].

- Consequence generally means a set of negative impacts of the risk occurrence.

The general illustration of DRC chain could be described as follows: Each of those negative facts is due to one (or several) event(s) that trigger(s) one (or several) risk(s); This (or these) risk(s) occur(s) because the considered area/system is concerned by one (or several) danger(s) that affect(s) one (or several) stake(s) [7].

Furthermore, the DRC chain could indicate the susceptibility to danger, which means the state of being very likely to be influenced or affected by danger. The following example in enterprise collaborative context illustrates susceptibility to danger (see Fig.2).

Company $C$ is the only one able to produce Product $P$ for the core company $C C$, which is a danger for the stake $C C$ because its Product $P P$ must be produced by using $P$. Consequently, the risk is that $P P$ may not be produced. It would be triggered if $\mathrm{C}$ decides not to produce $P$ anymore (an event occurs), then cause a consequence as 
which $C C$ cannot sell $P P$ to its customers. For this general illustration of DRC chain, the demand side $C C$ is susceptible to the danger of which there is no alternative provider regarding its required product. Different stakes have different degrees of susceptibility to danger while some stakes are not susceptible to danger.

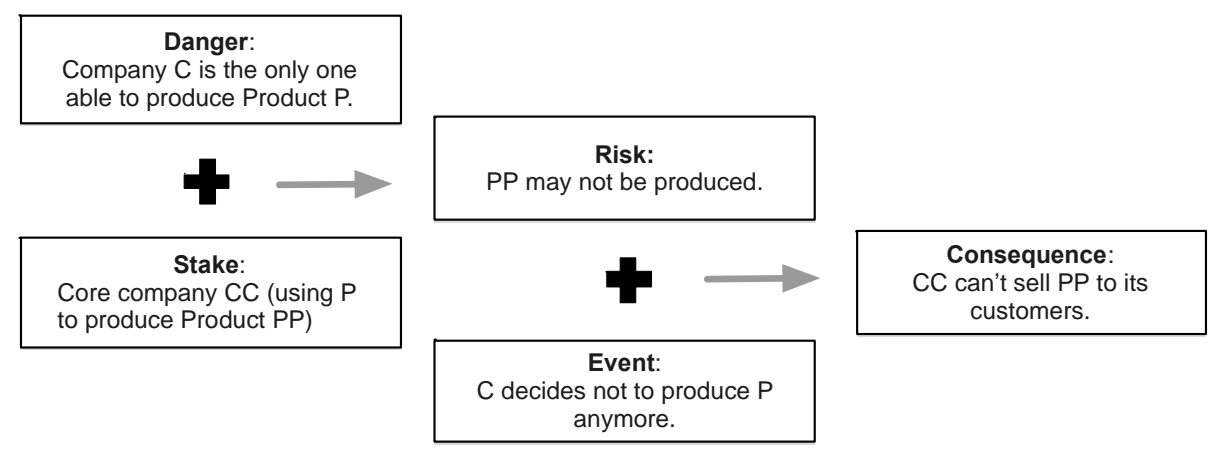

Fig. 2. An illustration of "susceptibility to danger" in DRC chain

\subsection{Interconnections in DRC Chain}

In the schema of the DRC chain, risk is created by danger and stake while consequence is created by risk and event. It can be seen that risk and consequence are the "generated" elements. Therefore, they are the ones which directly impact the considered system. Accordingly, it is worth to focus on what effects that they might create. One of perspective that can indicate it is cascading effects that could be described as multiple connections initiated by risk and consequence in the DRC chain.

A cascading effect is an inevitable and sometimes unforeseen chain of events due to an act affecting a system [25]. If there is a possibility that the cascading effect will have a negative impact on the system, it is probable to analyze the effects with a risk or consequence analysis. Fig. 3 shows six connections initiated from consequence (see connections (1)(2)(3)) and risk (see connections (4)(5)(6)), in order to present the cascading effect as follows: consequence and risk are regarded as the causal sources that target at danger, stake and event.

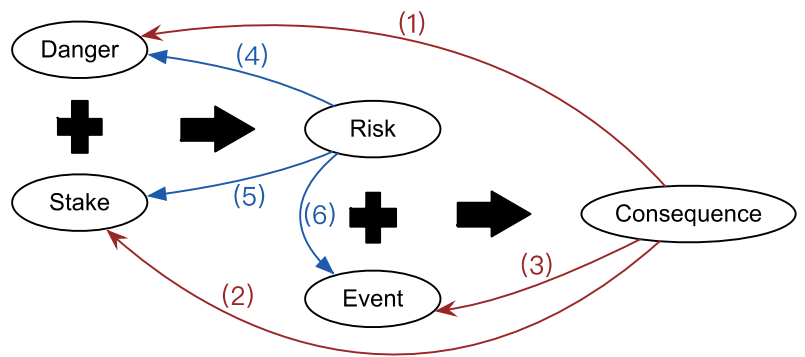

Fig. 3. Interconnections in DRC chain 
To illustrate the cascading effect further, three use cases are presented in Fig.4, which are the real ones from a cosmetic French company. The interconnections between the first two use cases (see connections (1)(2)(3) of Fig.4) could indicate consequence as the causal source. The first use case is already described in previous section, the consequence of which is that $C C$ cannot sell $P P$. It is worth mentioning that this consequence could bring about the next use case.

The second use case is described as follows: $C C$ has to contract with another company $C^{\prime}$ that can produce $P$, however, which is a danger for the new provider $C$ '. Concerning this stake, the danger could be manifested as a risk that its Product $P$ may decline in quality. Under this circumstance, if there is a big demand for $P$ from $C C$, the risk would be triggered and cause a consequence as which $C^{\prime}$ produces lower quality products and its image might be degraded.

In summary, it can be seen that one consequence in a scenario could create a new danger ( $C C$ contracts with $C^{\prime}$ ), also a new stake (company $C^{\prime}$ ) and even an event (big demand from $C C$ ), which lead to another risk-related scenario.

The third use case is described as follows: A huge workload of employees in Company $C^{\prime}$ is a danger for the stake $C^{\prime}$, because it could create a risk that the employees may go on strike for salary increase. The risk would be triggered if $C$ ' requires them to work overtime (an event), then a consequence of employees' strike might be caused.

Regarding risk as the causal source, the creation of danger, stake and event is generally due to the actions of risk prevention and mitigation. The interconnections between these three use cases (see connections (4)(5)(6) of Fig.4) could indicate it as below:

- Risk-danger: $C^{\prime}$ is confronted with a risk that its products may decline in quality in the second use case. In order to prevent the risk, $C^{\prime}$ might increase the workload of its employees to ensure the products' quality, which is a new danger shown in the third use case.

- $\quad$ Risk-stake: $C C$ needs to find the other company that can also produce its required Product $P$ in order to prevent the risk in the first use case ( $P P$ may not be produced). As a result, the risk creates a new stake Company $C^{\prime}$ that is shown in the second use case.

- $\quad$ Risk-event: For the sake of qualified quality of Product $P, C^{\prime}$ might requires its employees to work overtime. Consequently, the risk in the second use case ( $P$ by $C^{\prime}$ may decline in quality) creates an event in the third use case. 


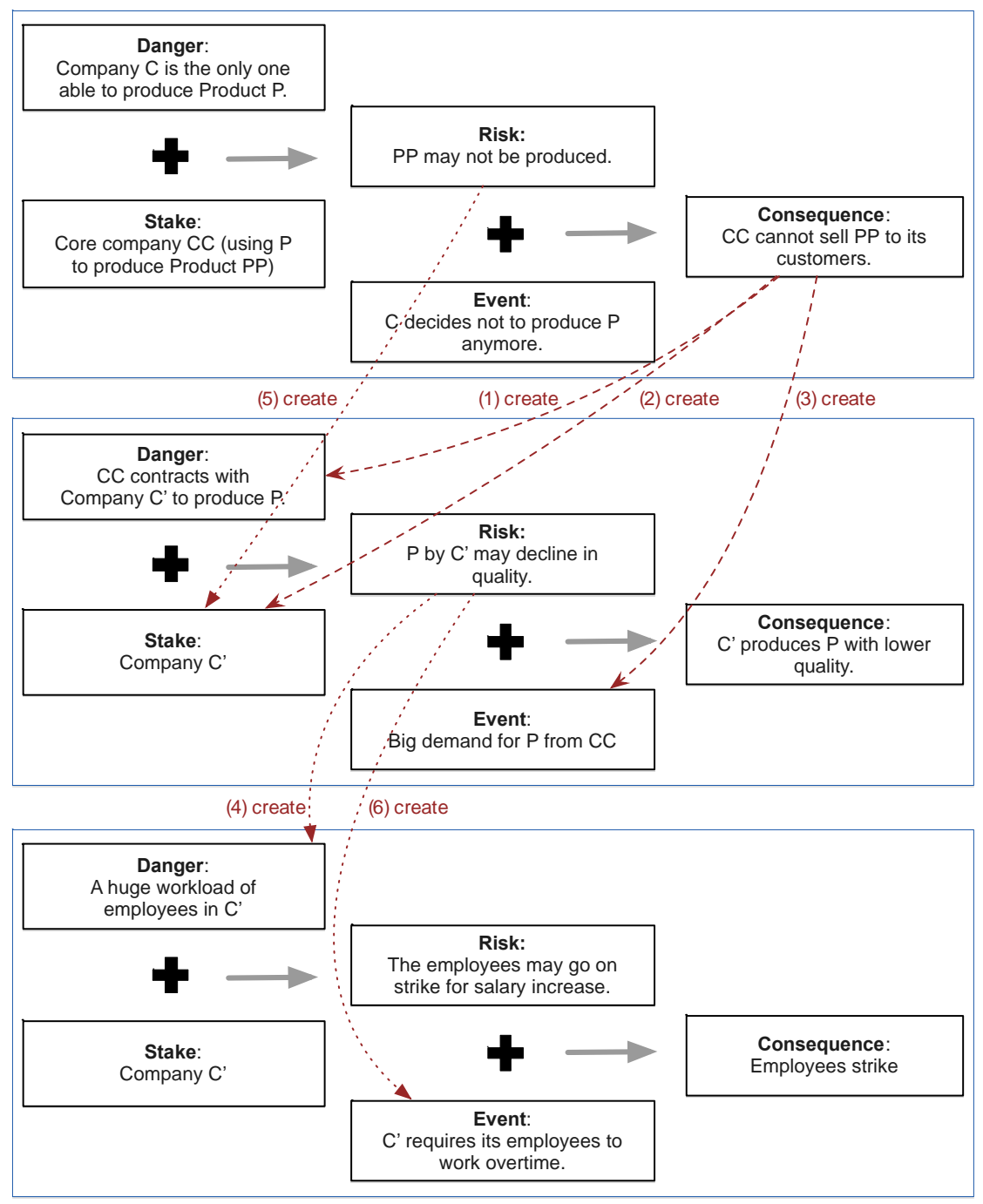

Fig. 4. An illustration of cascading effect in DRC chain

In addition to the interrelationship "create" between consequence/risk and danger/stake/event, there are some other interrelationships presented in Table 1. We define the interrelationships in DRC chain as follows:

- "Create": Consequence/risk makes new danger/stake/event happen.

- "Update": Consequence/risk makes danger/stake/event from one state or form into another.

- "Delete": Consequence/risk removes or makes danger/stake/event invisible.

"Yes" in Table 1 means that we have found the use cases to support this type of interconnection (it cannot be all shown in this article). Accordingly, "No" in Table 1 
means that the interrelationship does not exist between the concepts. To conclude, we hold that in considered scenario consequence or risk could create new danger, stake and event, and update or delete the current state or form of danger and stake. Nevertheless, event could not be updated or deleted because we cannot change what has happened before.

Table 1. Interrelationships in DRC chain

\begin{tabular}{l|lll|lll|lll}
\hline & \multicolumn{3}{|c|}{ Danger } & \multicolumn{3}{c|}{ Stake } & \multicolumn{3}{c}{ Event } \\
\hline & Create & Update & Delete & Create & Update & Delete & Create & Update & Delete \\
\hline Consequence & $(1)$ Yes & $(1)$ Yes & $(1) \mathrm{Yes}$ & $(2)$ Yes & $(2) \mathrm{Yes}$ & $(2) \mathrm{Yes}$ & $(3) \mathrm{Yes}$ & (3)No & (3)No \\
\hline Risk & $(4) \mathrm{Yes}$ & $(4) \mathrm{Yes}$ & $(4) \mathrm{Yes}$ & $(5) \mathrm{Yes}$ & $(5) \mathrm{Yes}$ & $(5) \mathrm{Yes}$ & $(6) \mathrm{Yes}$ & (6)No & (6)No \\
\hline
\end{tabular}

\section{Supply Chain Scenario Illustration}

Supply chain is considered as a specific form of collaborative network. It is a stable long-term network of enterprises each having clear roles in the value chain, covering all steps from initial product design and the procurement of raw materials, through production, shipping, distribution, and warehousing until a finished product is delivered to a customer [26].

In order to further illustrate the proposed DRC chain, three use cases of the supply chain scenario (presented in Fig. 5) would be given to be used to perform the progress of current work. Two partners are involved in this simple scenario: the core enterprise is the demand side, which submits orders to buy its required materials from the suppliers. Furthermore, the three use cases are described as follows:

- $\quad$ The first use case: Labor strike of suppliers is a danger for the core enterprise (a stake), because it would create the risk of the shortage of its required products. If the production disruption (an event) happens, the risk could be triggered. Then the consequence of overdue delivery cannot be avoided.

- $\quad$ The second use case: Shortage of products required by the core enterprise is a danger for the supplier who provides them (a stake). The risk is that the core enterprise might give a negative feedback in the evaluation of this supplier, and the risk occurs if overdue delivery from the supplier (an event) happens for several times. The core enterprise might consider to change the supplier to ensure its normal operation of business (a consequence).

- The third use case: Overdue delivery of supplier for long time is a danger for the core enterprise (a stake). It would create a risk that the core enterprise has to change the supplier. If many negative comments from the evaluation of the supplier (an event) are given to the decision-maker, the risk could be triggered. Consequently, the core enterprise needs to reselect the other suppliers to replace the tasks of the original supplier as soon as possible (a consequence). 
By comparing with the three use cases (presented in Fig. 5) and referring to the cascading effect in DRC chain (presented in Fig. 3), it can be seen that a target or outcome in one situation could be the causal source to connect another situation. Accordingly, several interconnections could be concluded:

- Consequence-danger and Consequence-event: The consequence of overdue delivery in the first use case could create a danger in the third use case (see connection (1)), and also create an event in the second use case (see connection (3)).

- $\quad$ Risk-danger: The risk of shortage of required products in the first use case could create a danger in the second use case (see connection (4)).

- Risk-event: The risk of negative evaluation in the second use case could create an event in the third use case (see connection (6)).

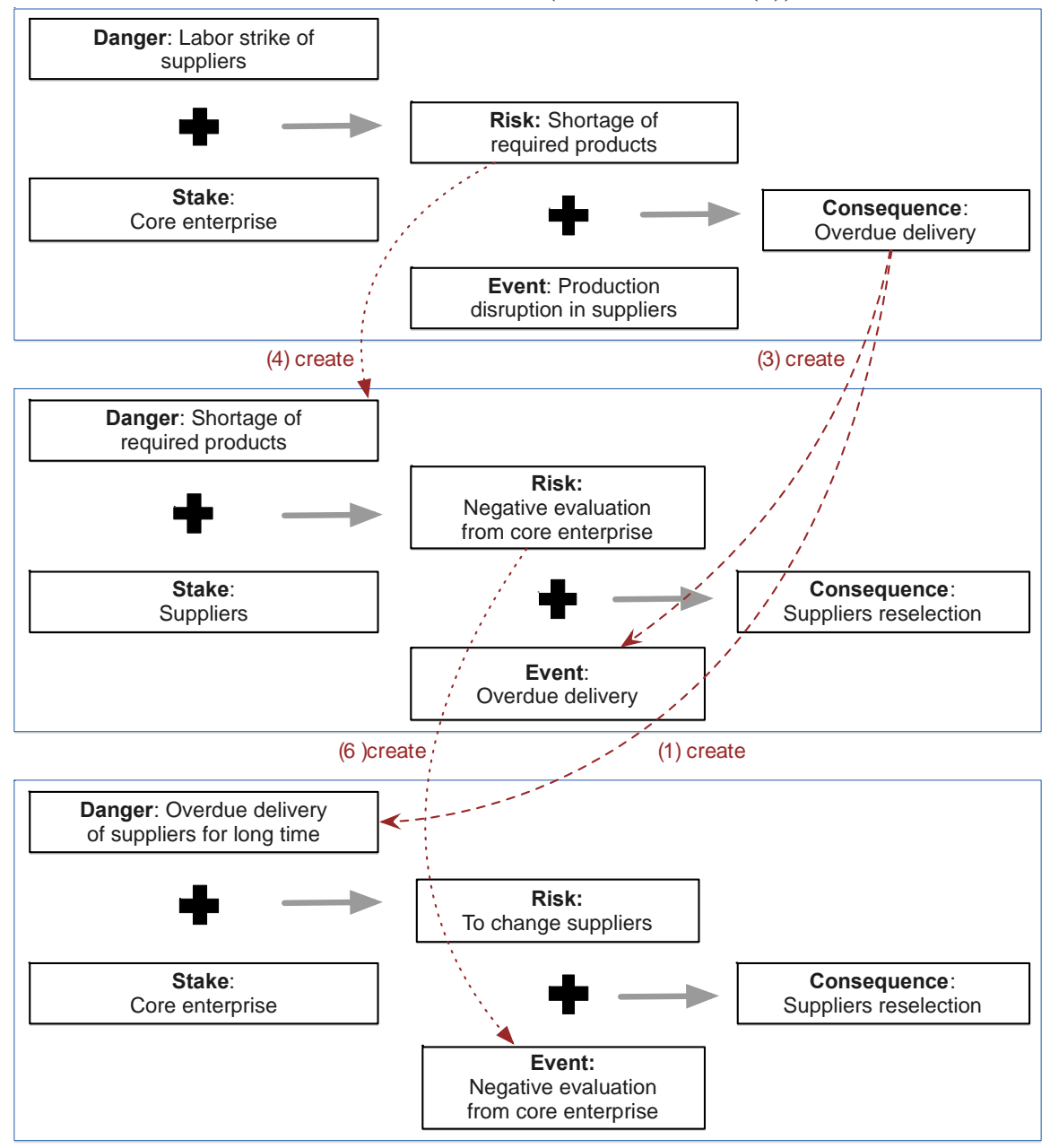

Fig. 5. Use cases illustration of supply chain scenario 


\section{Conclusion}

The presented framework of risk identification approach might be considered as a formalizing reference dedicated to identify and mitigate risk in collaborative networks. The proposed approach is compliant with the schema of Danger/Risk/Consequence chain that helps to formalize the risk-related knowledge that includes five concepts (danger, stake, risk, event and consequence) and their interrelationships. Cascading effect could be indicated in DRC chain, which could contribute to a deeper understanding of risk-related collaborative contexts. Besides, the devised danger typology and stake typology can be further used to develop a risk knowledge base for risk identification of collaborative networks. Furthermore, the risk knowledge base combined with the current methodology of metamodeling could contribute to further explore the ways in which an effective mechanism that can motivate diverse partners in collaborative networks to manage risks collaboratively.

The future works would use System Dynamics [27] to develop the proposed approach, which focus on: (i) developing a danger typology and a stake typology by synthesizing the growing diverse literatures; (ii) the deduction of interconnection rules of dangers and stakes in order to build a risk knowledge base for collaborative networks; (iii) developing risk identification rules based on the risk knowledge base; (iv) metamodeling with risk knowledge base that can be dedicated to support collaboration of partners, and deduce the collaborative processes of risk mitigation.

Acknowledgments. The presented research works have been supported by "the Fundamental Research Funds for the Central Universities of China". The authors would like to thank the project partners for their advice and comments.

\section{References}

1. Camarinha-Matos, Luis M. and Afsarmanesh, H.: On reference models for collaborative networked organizations. International Journal of Production Research, 46, 9, 2453-2469 (2008).

2. Jamshidi A., Abbasgholizadeh Rahimi S., Ait-kadi D., Ruiz A.: A New Decision Support Tool for Dynamic Risks Analysis in Collaborative Networks. In: Camarinha-Matos L., Bénaben F., Picard W. (eds) Risks and Resilience of Collaborative Networks. IFIP Advances in Information and Communication Technology, vol. 463. Springer, Cham (2015).

3. Wulan, M. and Petrovic, D.: A fuzzy logic based system for risk analysis and evaluation within enterprise collaborations. Computers in Industry, 63, 8, 739-748 (2012).

4. Rao, S. and Goldsby, T. J.: Supply chain risks: a review and typology. International Journal of Logistics Management, 20, 1, 97-123 (2009).

5. Juttner, U., Peck, H. and Christopher, M.: Supply chain risk management - outlining an agenda for future research. International Journal of Logistics: Research and Applications, 6,4, 197-210 (2003).

6. Zeng, B. and Yen, P. C.: Rethinking the role of partnerships in global supply chains: a risk-based perspective. International Journal of Production Economics, 185, 52-62 (2017). 
7. Bénaben, F., Barthe-Delanoë, A. M., Lauras, M. and Truptil, S.: Collaborative Systems in Crisis Management: A Proposal for a Conceptual Framework. Collaborative Systems for Smart Networked Environments, pp. 396-405. Springer Berlin Heidelberg (2016).

8. Vesely, W.E., Goldberg, F.F., Roberts, N.H., Haasl, D.F.: Fault Tree Handbook. Office of Nuclear Regulatory Research (1981).

9. Turoff, M., Bañuls, V. A., Plotnick, L., Hiltz, S. R. and Huerga, M.R.D.L.: A collaborative dynamic scenario model for the interaction of critical infrastructures. Futures, 84, 23-42 (2016).

10. Bénaben, F., Lauras, M., Truptil, S. and Salatge, N.: A Metamodel for Knowledge Management in Crisis Management. Hawaii International Conference on System Sciences, 126-135. IEEE Computer Society (2016).

11. Lauras, M., Bénaben, F., Truptil, S., Lamothe, J., Macé-Ramète, G. and Montarnal, A.: A meta-ontology for knowledge acquisition and exploitation of collaborative social systems. International Conference on Behavior, Economic and Social Computing (pp.1-7). IEEE (2015).

12. Edwards, P. J. and Bowen, P. A.: Risk management in project organisations. Elsevier, Oxford, UK (2005).

13. Rosas J., Urze P., Tenera A., Abreu A., Camarinha-Matos L.M.: Exploratory Study on Risk Management in Open Innovation. In: Camarinha-Matos L., Afsarmanesh H., Fornasiero R. (eds) Collaboration in a Data-Rich World. PRO-VE 2017. IFIP Advances in Information and Communication Technology, vol. 506, pp.527-540. Springer, Cham (2017).

14. Fang, C., Marle, F., Zio, E. and Bocquet, J. C.: Network theory-based analysis of risk interactions in large engineering projects. Reliability Engineering \& System Safety, 106(2), 1-10 (2012).

15. Yang, R. J. and Zou, P.: Stakeholder-associated risks and their interactions in complex green building projects: a social network model. Building \& Environment, 73, 1, 208-222 (2014).

16. Zhang, X., Yang, Y., and Su, J.: Risk identification and evaluation of customer collaboration in product development. Journal of Industrial Engineering and Management, 8, 3, 928-942 (2015).

17. Yang, R. J., Zou, P. X. W. and Wang, J.: Modelling stakeholder-associated risk networks in green building projects. International Journal of Project Management, 34, 1, 66-81 (2016).

18. Zhao, G., Liu, S., Lopez, C., Zhao, G., Liu, S. and Lopez, C., et al.: A Literature Review on Risk Sources and Resilience Factors in Agri-Food Supply Chains. In: CamarinhaMatos L., Afsarmanesh H., Fornasiero R. (eds) Collaboration in a Data-Rich World. PROVE 2017. IFIP Advances in Information and Communication Technology, vol. 506, pp.739-752. Springer, Cham (2017).

19. Wang, X., Xia, N., Zhang, Z., Wu, C. and Liu, B.: Human safety risks and their interactions in china's subways: stakeholder perspectives. Journal of Management in Engineering, 33, 5 (2017).

20. Scott, J.: Social network analysis: A handbook, Sage, Thousand Oaks, CA (2000)

21. Zhou, X. and Lu, M.: Risk evaluation of dynamic alliance based on fuzzy analytic network process and fuzzy TOPSIS. Journal of Service Science \& Management, 05, 3, 230-240 (2012).

22. ISO 3864-2, Technical Committee, ISO/TC 145/SC 2, Graphical symbols - Safety colours and safety signs (2016).

23. ISO 41011, Technical Committee, ISO/TC 267, Facility management - Vocabulary (2017). 
24. Lahmar, A., Galasso, F., Chabchoub, H. and Lamothe, J.: Towards an Integrated Model of Supply Chain Risks: An Alignment Between Supply Chain Characteristics and Risk Dimensions. In: Camarinha-Matos L., Bénaben F., Picard W. (eds) Risks and Resilience of Collaborative Networks. IFIP Advances in Information and Communication Technology, vol. 463, pp.3-16. Springer, Cham (2015).

25. Cascade effect. A Dictionary of Ecology. Encyclopedia.com.

26. Camarinha-Matos, L. M., Afsarmanesh, H., Galeano, N. and Molina A.: Collaborative Networked Organization -Concepts and Practice in Manufacturing Enterprises. Computers \& Industrial Engineering, 57, 1, 46-60 (2009).

27. Forrester, J.: System dynamics, systems thinking, and soft OR. System dynamics review, 10(2-3), 245-256 (1994). 